\title{
Buccal mucosa is a promising graft in Peyronie's disease surgery. Our experience and a brief literature review on autologous grafting materials
}

\author{
Andrea Fabiani ${ }^{1}$, Lucilla Servi $^{1}$, Fabrizio Fioretti ${ }^{1}$, Valentina Maurelli ${ }^{1}$, Flavia Tombolini ${ }^{2}$, \\ Alessandra Filosa ${ }^{3}$, Alessandro Zucchi ${ }^{4}$, Gianni Paulis ${ }^{5}$, Gabriele Mammana ${ }^{1}$ \\ ${ }^{1}$ Urologic Unit, Surgical Dpt, ASUR Marche Area Vasta 3, Macerata Civic Hospital, Italy; \\ ${ }^{2}$ Urologic Clinic, Politechnic University of Marche Region, Ancona, Italy; \\ ${ }^{3}$ Pathologic Unit ASUR Marche Area Vasta 3, Macerata Civic Hospital, Italy; \\ ${ }^{4}$ Urologic and Andrologic Clinic University of Perugia, Italy; \\ ${ }^{5}$ Regina Apostolorum Hospital, Andrologic Center, Albano Laziale, Roma, Italy.
}

\begin{abstract}
Summary Aim: Peyronie's Disease (PD) is an under reported acquired benign condition that, at the moment, is not curable with medical therapy.

Surgery represent the gold standard of treatment. Surgical approaches are several and they consist in "plication techniques" or plaque incision/excision with grafting of resulting albuginea defect. Among grafting procedures, albuginea defect substitution with autologous materials demonstrated over the years not inferior results respect to heterologous grafts. Buccal mucosa graft (BMG) is not usually emphasized in many review articles and clinical series are yet limited.

Methods: We present our experience with seventeen plaque incision procedures and BMG in surgical correction of complex penile curvatures due to $P D$ performed in a period of 30 months. Our analyses was focused on buccal mucosa graft characteristics as major determinant of the surgical success. We also conducted a brief literature review on autologous grafting materials used in reconstructive penile surgery for PD.

Results: Our cosmetics and functional results consists in a $100 \%$ of functional penile straightening with no relapses and $5,8 \%$ of de novo erectile dysfunction. Mean age was 56.4 years, mean follow-up of 22.5 (6-36) months. No complications graft related were observed. Operative time was 115.3 minutes in mean. Over $94 \%$ of patients referred they were "really much better" and "much better" satisfied based on PGI-I questionnaire administrated at the last follow-up visit.

Conclusion: BMG is revealing as an optimal choice for reconstructive surgery in $P D$. Anatomical characteristics consisting in the great elasticity, the quick integration time and the easy harvesting technique lead to high cosmetics and functional success rate, without omitting economical and invasiveness aspects.
\end{abstract}

KEY WORDS: Buccal mucosa; Graft; Peyronie disease; Autologous materials; Surgery.

Submitted 23 October 2015; Accepted 16 January 2016

No conflict of interest declared.

\section{INTRODUCTION}

Peyronie's Disease (PD) is an acquired benign condition that presents with a palpable induration and curvature or indentation of the erect penis (1). The average age of men affected by this disease is approximately 50-55 years and prevalence varies between 3,2\% and $13 \%$ (2). However, the disease is under reported as a consequence of embarassement felt by affected men (3). More cases are being identified with the advent of PDE5 inhibitors (PDE5-i) requests for erectile dysfunction treatment (1). Moreover, there is an increasing number of cases diagnosed in the younger population ( $<40$ years) due to the modification of demographic and social contexts determining a better understanding and information on PD (4). At the present, there is no cure for PD. The medical best approach seems to be "multimodal therapy" that is able to achieve greater results than any single drug alone tested in scientific literature (5-6). Surgery represent yet the gold standard of treatment. Surgical approaches are several, consisting in "plication techniques" or plaque incision/excision with grafting of determined albuginea defect. Indications for surgery are well established and the goal is to reliably and rapidly restore a coital function with a satisfactory and comfortable erection for both patient and partner (7). In our surgical practice, we had focused the attention on grafting techniques with buccal mucosa. As in case of medical therapy, because of data variability obtained from the wide range of autologous and heterologous grafts, we are inable to define which is the real "gold standard" for albuginea substitution. From literature, it is possible to note that biocompatible materials do not provide better outcomes in terms of satisfaction or postoperative erectile dysfunction (ED) than autologous grafts (8-9). Moreover, many studies did not include complete information about the outcome of surgery such as satisfaction rate or globally post operative ED. When published, the outcomes are comparable, especially between pericardial graft (10-11) and buccal 
mucosa graft series (12-13). In the present paper we explain how the characteristics of an ideal graft were achieved with this surgical procedure and outcomes data obtained from our series of 17 patients who underwent a complex corporoplasty using a buccal mucosa graft, compared with literature results. We had also conducted a literature review on autologous graft materials focusing on the buccal mucosa patch characteristics respect the main autologous graft employed in reconstructive penile surgery for PD.

\section{MATERIAL AND METHODS}

We have evaluated the clinical, pathological, intraoperative and post surgical data of a series of 17 consecutive cases treated with a plaque incision/partial excision and buccal mucosa grafting in the correction of severe secondary penile curvatures due to a stabilized PD and not responders to other medical treatment or previous surgical procedures. In a period of 30 months, in our Urologic Center we performed 17 plaque incision and grafting procedures after a training of 3 cases (not included in this report) carried out under the supervision of the Author (AZ) skilled in the technique. All surgical procedures were performed by the same equipe (AF, LS, FF) and each member was employed alternatively in buccal mucosa harvesting time or in penile corporoplasty and grafting. The pre-operative work-up included a clinical examination, a detailed clinical history, the IIEF (IIEF-5) questionnaire and penile ultrasound scans in tumescence and PGEl-induced erection $(10 \mathrm{mcg}$ ) to determine plaque dimensions, curvature, erection hardness score (EHS) (14) and vascular penile status. Ultrasonographic plaque patterns was defined according on Bekos classification (15). The grafts needed were harvested as described by Eppley et al. (16). The corporoplasty procedures were done essentially the same way as for all others grafting techniques (17). Circumcisions were made by a "sleeve technique" or a "forceps-guided method". Dorsal neurovascular bundle was ever elevated in a centripetal manner. In case of ventral curvature, urethra was carefully isolated from corpora cavernosa. The relaxing incision was made as a double $\mathrm{Y}$ or $\mathrm{H}$ shaped at the point of maximum curvature. The margins of the incision are carefully prepared on all sides, preserving the underlying erectile tissue. After "defatting", buccal mucosa patch was apposite to cover the albuginea defect with the submucosa surface in contact with the cavernous tissue in order to obtain a quick blood supply and sutured with a 3/0 adsorbable sutures in each of four sides of the graft. Artificial erection was repeated in order to evaluate the curvature and deformity correction, defining the need of complementary tunica albuginea plications. Buck's fascia was closed with interrupted adsorbable suture or urethra was fixed to corpora cavernosa with tension free stitches. A drainage was placed between the Buck's fascia and the dartos in order to facilitate secretion discharge. Circumcisional incision was closed and a "mummy wrap" with a non sticky dressing was performed around the base to the circumcision site (18). Penis was located in a ventralized position. Patients were discharged at third post operative day after catheter, drainage and dressing removal. The time of spontaneous erection resumption was recorded for each patient. To improve blood supply to the graft a low-dose PDE5-i was prescribed for all patients for a period of two months, starting immediately after discharge. Check-ups were scheduled every 3 months. After 6 and 12 months patients underwent to a penile echo- color- Doppler ultrasound dynamic scan (EHS determination) and compiled the IIEF-5 and the PGI-I (Patient's Global Impressions of Improvement questionnaires), a 1-item questionnaire designed to assess the patient's impression of changes in his own condition (19). Finally partner satisfaction was assessed (very satisfied, satisfied, fairly satisfied, dissatisfied) at each control. After 1 year, check-ups were scheduled at 12 month intervals. Literature review on autologous graft materials employed in reconstructive penile surgery for PD was conducted using key words "graft", "corporoplasty", "buccal mucosa", "autologous materials".

\section{Results}

During a 30 months period, seventeen patients underwent complex corporoplasty with buccal mucosa graft. Pre-operative data, operative times, complications, and post operative findings are summarized in Table 1 and Table 2. The mean age was 56.4 years (range $45-71$ ) and the mean follow-up was 22.5 months (range 6 - 36). All patients had sexual activity with valid erections with or without PDE5-I assumption. PDE5-I use was declared in medical history by 10 patients before surgery $(58,8 \%)$. After curvature correction, PDE5-I frequency use was confirmed and introduced in one more patient because of de novo erectile dysfunction. In all the cases the procedure was indicated because of great difficult during sexual intercourse caused by penile curvature. All patients previously received a peri-plaque medical treatment with verapamil (70.5\%) or pentoxiphilline (29.5\%). An immediate post operative complication developed in one patient at the cheek (donor site). Resolution was obtained by an haemostatic suture performed 3 hours after the ending of corporoplasty. Penile haematoma with spontaneous resolution was observed in one case. At last follow-up no relapses were recorded. One patient refers a worsening of erectile function (IIEF score 15) nevertless the EHS assessed was the same than in preoperative evaluation. All other patients had complete spontaneous erections 4-5 days after surgery without use of any device. Mean operative time was 115.3 minutes (range 80-165). Mean plaque volume was $151.45 \mathrm{ml}$. About PGI-I questionnaire, at last follow-up, over $94 \%$ of patients referred they were "really much better" and "much better" (Table 3) and 76,5\% of partners were satisfied (64,7\% "very satisfied"). Only one partner reported no change in sexual satisfaction after surgical curvature correction.

\section{Discussion}

Reconstructive surgery represents the gold standard of therapy in PD in cases of failure of conservative approach in restoring penetrative and coital capacity. When PD is a stabilized disease, the three basic surgical approaches are 
Table 1.

Pre-operative patient's characteristics and surgical informations.

\begin{tabular}{|c|c|c|c|c|c|c|c|c|c|c|c|}
\hline Pts & Age & $\begin{array}{c}\text { Medical } \\
\text { history/ } \\
\text { treatment for PD }\end{array}$ & $\begin{array}{l}\text { Site of } \\
\text { curvature }\end{array}$ & $\begin{array}{l}\text { Degree of } \\
\text { curvature }\end{array}$ & $\begin{array}{l}\text { IIIEF-5 } \\
\text { Score }\end{array}$ & EHS* & $\begin{array}{c}\text { Operative } \\
\text { time (minutes) }\end{array}$ & $\begin{array}{l}\text { Duration } \\
\text { of disease } \\
\text { (months) }\end{array}$ & $\begin{array}{c}\text { Bekos } \\
\text { plaque type }\end{array}$ & $\begin{array}{l}\text { Plaque } \\
\text { dimensions } \\
(\mathrm{mm})^{* *}\end{array}$ & Complications \\
\hline 1 & 48 & & Dorsal & 60 & 24 & 4 & 140 & 16 & A & $\begin{array}{c}18 \times 15 \times 3.5 \\
(491.4 \mathrm{ml})\end{array}$ & $\begin{array}{l}\text { Haemorrage at } \\
\text { the donor site }\end{array}$ \\
\hline 2 & 54 & Dupuytren disease & Dorsal & 75 & 22 & 4 & 145 & 19 & $A$ & $\begin{array}{l}12 \times 4 \times 2 \\
(49.92 \mathrm{ml})\end{array}$ & - \\
\hline 3 & 71 & - & Dorsal & 50 & 18 & 2 & 140 & 18 & $C$ & $\begin{array}{c}12 \times 6 \times 3 \\
(112.32 \mathrm{ml})\end{array}$ & $\begin{array}{c}\text { De novo } \\
\text { erectile dysfunction }\end{array}$ \\
\hline 4 & 48 & $\begin{array}{c}\text { PDE5i use/ } \\
\text { radical prostatectomy }\end{array}$ & Dorsal & 60 & 20 & 3 & 150 & 14 & $B$ & $\begin{array}{l}8 \times 5 \times 2 \\
(41.6 \mathrm{ml})\end{array}$ & - \\
\hline 5 & 62 & $\begin{array}{c}\text { PDE5i use/ } \\
\text { traumatic event }\end{array}$ & Ventral & 45 & 23 & 4 & 165 & 12 & $A$ & $\begin{array}{c}10 \times 5 \times 3 \\
(78 \mathrm{ml})\end{array}$ & - \\
\hline 6 & 52 & - & Dorsal & 50 & 23 & 4 & 120 & 17 & $C$ & $\begin{array}{l}14 \times 6 \times 3 \\
(131 \mathrm{ml})\end{array}$ & - \\
\hline 7 & 55 & $\begin{array}{c}\text { PDESi use/ } \\
\text { diabetes mellitus }\end{array}$ & Dorsal & 50 & 22 & 4 & 95 & 13 & $C$ & $\begin{array}{c}9 \times 4 \times 3 \\
(56.16 \mathrm{ml})\end{array}$ & - \\
\hline 8 & 50 & - & Dorsal & 60 & 22 & 4 & 100 & 14 & $C$ & $\begin{array}{c}16 \times 6 \times 3 \\
(149.76 \mathrm{ml})\end{array}$ & $\begin{array}{l}\text { Penile shaft } \\
\text { haematoma }\end{array}$ \\
\hline 9 & 68 & $\begin{array}{c}\text { PDE5i use/ } \\
\text { diabetes mellitus }\end{array}$ & Dorsal & 45 & 24 & 4 & 80 & 18 & $B$ & $\begin{array}{c}20 \times 5 \times 2 \\
(104 \mathrm{ml})\end{array}$ & - \\
\hline 10 & 58 & $\begin{array}{l}\text { Previous plication } \\
\text { procedure/PDE5i use }\end{array}$ & Dorsal & 45 & 24 & 4 & 80 & 12 & $B$ & $\begin{array}{c}6 \times 4 \times 2 \\
(24.96 \mathrm{ml})\end{array}$ & $\begin{array}{l}\text { Glandular } \\
\text { erection pain }\end{array}$ \\
\hline 11 & 52 & PDE5i use & Dorsal-HG & 75 & 24 & 4 & 125 & 13 & C & $\begin{array}{l}18 \times 7 \times 2 \\
(131 \mathrm{ml})\end{array}$ & - \\
\hline 12 & 63 & $\begin{array}{l}\text { Phymosis/preputial } \\
\text { lichen sclerosus/ } \\
\text { PDE5i use }\end{array}$ & Dorsal-lateral & 85 & 18 & 2 & 135 & 16 & $C$ & $\begin{array}{c}25 \times 10 \times 3 \\
(390 \mathrm{ml})\end{array}$ & - \\
\hline 13 & 53 & HIV disease & Dorsal-HGD & 90 & 24 & 4 & 145 & 17 & $C$ & $\begin{array}{c}25 \times 9 \times 3 \\
(351 \mathrm{ml})\end{array}$ & - \\
\hline$\overline{14}$ & 57 & PDE5i use & Dorsal & 45 & 22 & 4 & 90 & 12 & $A$ & $\begin{array}{c}10 \times 5 \times 2 \\
(52 \mathrm{ml})\end{array}$ & - \\
\hline 15 & 68 & $\begin{array}{c}\text { PDE5i use/ } \\
\text { radical prostatectomy }\end{array}$ & Dorsal & 45 & 21 & 3 & 85 & 24 & A & $\begin{array}{l}11 \times 4 \times 2 \\
(45.76 \mathrm{ml})\end{array}$ & - \\
\hline 16 & 55 & PDE5i use & Dorsal & 60 & 23 & 3 & 85 & 48 & $B$ & $\begin{array}{c}6 \times 4 \times 2 \\
(24.96 \mathrm{ml})\end{array}$ & - \\
\hline 17 & 45 & - & Dorsal & 90 & 24 & 3 & 80 & 10 & $C$ & $\begin{array}{l}23 \times 10 \times 3 \\
(358.8 \mathrm{ml})\end{array}$ & - \\
\hline Mean & 56.4 & 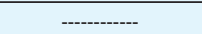 & -..- & 57.4 & & & 115.3 & 17.2 & -..-- & $151.45 \mathrm{ml}$ & - \\
\hline
\end{tabular}

* Erection hardness score.

** Plaque dimensions were recorded during pre operative ultrasound evaluation and calculated considering the ellipsoid volume formula (volume is reported in ml). HGD: Hourglass deformity.

represented by excisional or incisional corporoplasty (i. e. Nesbit or Yachia procedures), plication techniques and plaque surgery procedures with or without graft materials employement (7). At the moment, no one surgical technique demonstrates superiority. Is it clear that when penis have a severe curvature $\left(>60^{\circ}\right)$ or deformity or it is affected by marked shortening or narrowing, plaque incision/partial excision and the graft of the resulting albuginea defect is the preferred surgical approach (20). Complete excision of the plaque should never be offered to patients, as it would then require a larger graft and therefore it is associated with an unacceptably high rate of post operative erectile dysfunction (21). Various graft materials have been used by many investigators. They may be Synthetic Inert Substances, allografts or xenografts, or tissues harvested from the patient (autologous materials) at the time of surgery with a presumed additional morbidity and an highest operative time. The ideal graft should be easy to harvest, be taken reliably, heal without contracture, resistant to infection and preserving erectile capacity (22). Despite a large amount of data obtained from numerous studies, ideal graft material has yet to be established. The most common Syntethic Inert Substances used are Goretex and Dacron while the most common autologous materials used are saphenous vein, dermis, buccal mucosa, rectus fascia and fascia lata. Bovine and cadaveric pericardium, porcine small intestine submucosa and cadaveric fascia lata represent the allo/xenograft more frequently employed (23). Each grafting material has its own advantages and drawbacks in 
Table 2.

Post operative erectile function and couple satisfaction.

\begin{tabular}{|c|c|c|c|c|c|c|c|c|c|}
\hline Pts & $\begin{array}{l}\text { Time of } \\
\text { spontaneous } \\
\text { erections } \\
\text { resumption (days) }\end{array}$ & $\begin{array}{c}\text { IIEF-5 } \\
\text { pre operative } \\
\text { score }\end{array}$ & $\begin{array}{c}\text { IIEF-5 } \\
\text { post operative } \\
\text { score at last } \\
\text { follow-up }\end{array}$ & $\begin{array}{l}\text { Patient } \\
\text { satisfaction } \\
\text { (PGI-I score) } \\
\text { at } 3 \text { months }\end{array}$ & $\begin{array}{l}\text { Patient } \\
\text { satisfaction } \\
\text { (PGI-I score) } \\
\text { at } 6 \text { months }\end{array}$ & $\begin{array}{c}\text { Patient } \\
\text { satisfaction } \\
\text { (PGI-I score) } \\
\text { at } 24 \text { months }\end{array}$ & $\begin{array}{l}\text { Global } \\
\text { follow-up } \\
\text { (months) }\end{array}$ & $\begin{array}{l}\text { Partners } \\
\text { satisfaction } \\
\text { at last follow-up }\end{array}$ & $\begin{array}{c}\text { EHS } \\
\text { score at last } \\
\text { follow-up }\end{array}$ \\
\hline 1 & 4 & 24 & 24 & 1 & 1 & 1 & 36 & 1 & 4 \\
\hline 2 & 3 & 22 & 22 & 1 & 1 & 1 & 36 & 1 & 4 \\
\hline 3 & 2 & 18 & 15 & 4 & 3 & 4 & 29 & 4 & 3 \\
\hline 4 & 3 & 20 & 24 & 1 & 1 & 2 & 29 & 2 & 4 \\
\hline 5 & 4 & 23 & 24 & 2 & 2 & 2 & 29 & 2 & 4 \\
\hline 6 & 4 & 23 & 24 & 2 & 2 & 2 & 25 & 3 & 4 \\
\hline 7 & 7 & 22 & 24 & 3 & 3 & 1 & 25 & 1 & 4 \\
\hline 8 & 5 & 22 & 23 & 2 & 2 & 1 & 25 & 1 & 4 \\
\hline 9 & 5 & 24 & 24 & 2 & 2 & - & 22 & 3 & 4 \\
\hline 10 & 3 & 24 & 24 & 2 & 2 & - & 18 & 1 & 4 \\
\hline 11 & 2 & 24 & 24 & 1 & 1 & - & 18 & 1 & 4 \\
\hline 12 & 2 & 18 & 24 & 1 & 1 & - & 18 & 3 & 3 \\
\hline 13 & 3 & 24 & 24 & 2 & 2 & - & 18 & 1 & 4 \\
\hline 14 & 3 & 22 & 24 & 1 & 1 & - & 12 & 1 & 4 \\
\hline 15 & 4 & 21 & 24 & 1 & 1 & - & 12 & 1 & 4 \\
\hline 16 & 4 & 23 & 24 & 1 & 1 & - & 7 & 1 & 4 \\
\hline 17 & 1 & 24 & 24 & 1 & 1 & - & 6 & 1 & 3 \\
\hline
\end{tabular}

Table 3.

Results of buccal mucosa (BM) grafting vs saphenous vein (SV) graft as reported in recent scientific literature.

\begin{tabular}{|c|c|c|c|c|c|c|c|}
\hline Authors (reference) & Graft & Patients & Mean follow-up (mo) & Straighteningof penis (\%) & Postop erectile dysfunction (\%) & Shortening of penis (\%) & Patient satisfaction (\%) \\
\hline Porena M. et al. (31) & SV & 12 & NA & $83 \%$ & 0 & 0 & NA \\
\hline Kadiog/u A. et al. (36) & SV & 22 & $>60$ & 72.8 & 13.6 & NA & 81.8 \\
\hline Kalsi J. et al. (37) & SV & 113 & 12 & 86 & 15 & 25 & 96 \\
\hline Montorsi F. et al. (38) & SV & 50 & $>60$ & 72 & 22 & 100 & 60 \\
\hline El Sakka al. et al. (39) & SV & 112 & 18 & 96 & 12 & 17 & 92 \\
\hline Akman T. et al. (40) & SV & 56 & 37.1 & 73 & 8 & NA & NA \\
\hline Adeniyi AA. et al. (41) & SV & 51 & 16 & 82 & 8 & 35 & 92 \\
\hline Akkus E. et al. (42) & SV & 50 & 32 & 80 & 6 & 40 & 88 \\
\hline De Stefani S. et al. (43) & SV & 8 & 13 & 87.5 & 0 & 0 & 100 \\
\hline Yourkanin JP. et al. (44) & SV & 22 & 13.4 & 66.6 & 46 & 0 & NA \\
\hline Shioshvili TJ et al. (28) & BM & 26 & 38.4 & 93.6 & 7.7 & 15.4 & NA \\
\hline Liu B. et al. (29) & BM & 24 & 6- 84 & 87.5 & 12.5 & 12.5 & 100 \\
\hline Cormio L. et al. (12) & BM & 15 & 12.1 & 100 & 0 & 0 & 93.3 \\
\hline Zucchi A. et al. (13) & BM & 28 & 43 & 96.5 & 3,5 & 0 & 85 \\
\hline Present series & BM & 17 & 22.5 & 100 & 5,9 & 0 & 94 \\
\hline Gvasalia B. et al. (45) & BM & 33 & 42 & 100 & 18 & 15 & 85 \\
\hline
\end{tabular}

terms of availability, antigenicity and cost effectiveness. Buccal mucosa is used for reconstructing oral and maxillofacial defects, repairing the conjuctival mucosa of the eye, oral pharyngeal reconstructive surgery and reconstructing vaginal defects (24-25-26-27). In 2005, buccal mucosa was introduced as free autograft in the surgical treatment of PD (28) and then, during the years, evaluated in several others series (12-13-29). Results were very interesting since from data reported by Shioshvili and collegues (28). After the surgical treatment, with a mean follow-up of more than 3 years, they observed the complete straightening of the penis in $92.3 \%$ of 26 patients treated with a residual curvature $\left(<10^{\circ}\right)$ in two cases $(7.7 \%)$, the shortening of penis in four patients (15.4\%) and in two patients a partial reduction of erectile power (7.7\%). They concluded that their plaque excision and graft with buccal mucosa technique, showing high properties of adaptation and revascularization, good anatomical and functional clinical results, and demonstrating a stable elasticity without shrinkage, is simple and can be recommended for wide use in clinics for surgical treatment of PD. Similarly, Liu et al. (29) performed the surgical replacement of the plaque by free autograft of buccal mucosa on 27 patients with Peyronie's disease, ranging in age from 
24 to 72 years (mean 53), varying in disease course between 1 and 13 years, with a penile curvature angle of $30^{\circ}-80^{\circ}$ in erection. Satisfactory results were achieved in all the cases, with no such complications as hematoma, infection, oral numbness, and tightness of the mouth. Of the 24 cases evaluated, with a follow-up ranging from 6 months to 7 years, complete straightening of the penis was achieved in 21 , slight residual curvature $(<15$ degrees) was noted in $3(12,5 \%)$, a little shortening of the penis $(<1 \mathrm{~cm})$ in $2(8,3 \%)$, and erectile pain in 3 cases $(12,5 \%)$. The Authors underlined in they conclusions the stable elasticity and no shrinkage of buccal mucosa graft. Modifying the procedure from a plaque excision with substitution to an incision with insertion of a buccal mucosa patch, Cormio and co-workers (12) reported in 15 patients, operated without complications (56.3 years of mean age and $72^{\circ}$ of mean penile curvature degree), a $100 \%$ of penile straightening, $1.8-\mathrm{cm}$ mean increase in length of affected side, no curvature recurrence or de novo erectile dysfunction, 1.6 mean increase in IIEF-5 score, and patient and partner satisfaction of $93.3 \%$ and $100 \%$, respectively. These results were recently confirmed by Zucchi et al. (13) in 32 patients treated with this procedure between 2006 and 2013. In their evaluable 28 cases, they reported no complications and a curvature relapse, after 1 year, in 3.5\%. IIEF scores improved significantly after 1 year confirming stability in 50\% of cases after 2 years. Patients satisfaction was $85 \%$ on PGI-I questionnaire. They concluded that corporoplasty with buccal mucosa represent a good treatment choice for most forms of PD. Gvasalia et al. (45) confirmed the previous good results. In a population study of 33 patients with a 43 months of mean follow-up, they reported a satisfaction rate of $85 \%$. Complete penis straightening was achieved in $73 \%$, with a residual curvature $\left(<20^{\circ}\right)$ in $27 \%$. And post operative erectile dysfunction was observed in $18 \%$ with a good response to PDE 5 inhibitors. Authors underline that erectile dysfunction was common in elderly patients. Also in our present work we are able to confirm these favorable results even if our series includes a non selected population. In fact, surgical procedures were performed in patients who required surgical correction of a curvature causing a great difficult during sexual intercourse or psychological impairment. Patients are variably aging, with a medical general history characterized from different comorbidities as diabetes mellitus, cardiovascular disease, HIV or previous pelvic surgical procedure for prostate cancer. One patient underwent a previous failed plication procedure. Pre-operative use of PDE5 inhibitors was referred by 10 patients (58.8\%). Thus, considering that recognized risk factor of post operative erectile dysfunction are pre operative sexual function, patients age and operative technique (larger and ventral graft) (21), the probability of de novo erectile dysfunction was high in several patients of our study. In contrast, results obtained were very comfortable. Rate of functional penis straightening was $100 \%$. De novo erectile dysfunction was registered only in one case $(5.9 \%)$ in which EHS recorded at follow-up was the same than pre operatively anyway. Satisfaction for both patient and partner was achieved. Globally, in terms of overall success rate, BMG series reported results between $87.5 \%$ and $100 \%$
(Table 3). Patient satisfaction rate ranged from $85-100 \%$ when investigated (12-13) and no decrease is observed over the years. The rate of "de novo" erectile dysfunction ranged between $0 \%$ to $18 \%$. No patch bulging are yet reported. Only a case of "seroma" was cited but not reported (13). Loss of glans sensitivity or recurrent erection penile pain were common symptoms reported by the patients, especially in the first three or six months from the intervention. As observed in our experience, they are related to surgical procedure "per se" (eg. plaque location near to glans or attached to dorsal neurovascular bundle, requiring difficult dissection) and not directly to the patch. These symptoms are safely managed with the common analgesic/anti-inflammatory drugs. At the least, the need of a multiple harvesting from cheek is very rare and the elasticity of buccal mucosa permits to avoid any patch oversizing respect to plaque dimensions (13). Prior of these evidences, the venous graft was advocated as the more physiologic than others autologous tissue (30-31). The advantages presented to support this use were several (32-35). As reported in Table 3, overall success rates for straightening of the penis with the use of saphenous vein grafting ranged between 66.6\% and 96\% (36-45). Despite promising theoretical properties, saphenous vein grafting clinical results are not so satisfactory. In fact, penile shortening occurs in $17-100 \%$ of cases and de novo erectile dysfunction in up to $46 \%$ of cases. In addition, the patient satisfaction rate in the short term ranged from $88 \%$ to $100 \%$ but it tends to decrease to $60-86 \%$ in the few series with a follow-up longer than 5 years (38). The major drawback of venous graft was the need for a second incision to harvest the vein, then the bulging of the graft, indentations or hourglass deformities, sensory loss and persistent pain (36). Compared with the others graft material, characteristics of buccal mucosa are more favorable, also considering the functional and cosmetic results as reported in our experience and in literature (Table 4 and related references in Supplementary Materials posted in www.aiua.it). Similarly to venous graft, the buccal mucosa is a living tissue with an elevated binding capacity and revascularization which is immediately supplied with blood from the cavernous tissue. As vital tissue, buccal mucosa tends to heal rapidly, immediately integrating with the surrounding albuginea tissue. This translates into a more rapid resumption of spontaneous erections (mean of 3.5 days in our experience) and sexual activity and into a reduced risk of curvature relapse and ED after surgery (13). The thickness of the buccal mucosa is nearly the same of the tunica albuginea favoring easy adaptation to all sides of albuginea's incision ensuring a perfect seal. These characteristics reduce the risk of curvature relapse and erectile dysfunction after surgery. Another advantage of the BMG is its low cost (47). Biocompatible materials are expensive and the rehabilitation to prevent scarring related retraction (48) implies the adjunctive cost of buying or hiring a vacuum device. Despite these evidences, BMG is not usually emphasized in many review articles and clinical series are yet limited. Many authors not understand the anatomic logic for use of buccal mucosa as a tunica albuginea substitutes (49) but it must take into account that, as noted by Cormio et al. (12), clinical experience with BMG was 
begun after having examined the "ideal" substitute of penile tunica albuginea in experimental animal models (50). In this experience, buccal mucosa obtained the best results in terms of elasticity, coefficient of lengthening, and morphological structure. Plaque excision and BMG was then applied in humans obtaining the reported very interesting cosmetic and functional results. In particular, as previously mentioned, we would like underlines the great elasticity of BMG that permits to harvest a patch with no need of oversizing respect plaque dimensions and the integration time allows a rapid resumption of spontaneous erections. Moreover, the absence of accessory wounds and severe complications at the side of patch harvest, lead us to consider BMG as a preferable option for PD surgery. In addition, operative time are no longer than these registered in others penile grafting procedures. We had observed a mean operative time of 115 minutes that we consider very acceptable for a complex surgical procedure that allows to restore a functional penile shaft for sexual intercourse. If in clinical setting also the surgeons expectations, so the reproducibility of surgical technique and the availability of the graft may be considered important, the first outcomes to be achieved in reconstructive surgery for PD are the patient perspectives in terms of patient's and partner satisfaction that, over the time, BMG seems able to assure.

\section{Conclusion}

Buccal mucosa graft is revealing as an optimal choice for reconstructive surgery in $\mathrm{PD}$, determining a high satisfaction rate over the time for both the patients and the partner. Anatomical characteristics consisting in the great elasticity, the quick integration time and the easy and reproducible harvesting technique lead to high cosmetic and functional success rate, without omitting economical and invasiveness aspects. Considering the not satisfactory results observed at the long term in cases of venous grafting procedures, we need an higher follow-up period and an higher number of cases treated with a BMG to define buccal mucosa a first choice in the surgical management of PD.

\section{REFERENCES}

1. Jalkut M, Gonzalez-Cadavid N, Rajfer J. Peyronie's Disease: A Review. Rev Urol. 2003; 5:142-8.

2. Dibenedetti DB, Nguyen D, Zografos L, et al. A population-based study of Peyronie's disease: Prevalence and treatment patterns in the United States. Adv Urol. 2011:1-9.

3. Greenfield JM, Levine LA. Peyronie's disease: etiology, epidemiology and medical treatment. Urol Clin North Am. 2005; 32:469-78.

4. Paulis G, Cavallini G, Barletta D, et al. Clinical and epidemiological characteristics of young patients with Peyronie's disease: a retrospective study. Res Rep Urol. 2015; 7:107-111.

5. Abern MR, Larsen S, Levine LA. Combination of penile traction, intralesional verapamil, and oral therapies for Peyronie's disease. J Sex Med. 2012; 9:288-295.

6. Paulis G, Farina FP, Cavallini G, et al. Pentoxifylline associated with Other Antioxidants (Multimodal Therapy) on Patients with Peyronie's Disease. Results of a Controlled Study. Andrology open access. 2014; 3:123.
7. Ralph D, Gonzalez-Cadavid N, Mirone V, et al. The management of Peyronie's disease: evidence based 2010 guidelines. J Sex Med. 2010; 7:2359-2374.

8. Levine LA, Larsen SM. Surgery for Peyronie's disease. Asian J Androl. 2013; 15:27-34.

9. Levine LA, Burnett AL. Standard operating procedures for Peyronie's disease. J Sex Med. 2013; 10:230-244.

10. Egydio PH, Lucon AM, Arap S. Treatment of Peyronie's disease by incomplete circumferential incision of the tunica albuginea and plaque with bovine pericardium graft. Urology. 2002; 59:570-574.

11. Chun JL, McGregor A, Krishnan R, Carson CC. A comparison of dermal and cadaveric pericardial grafts in the modified HortonDevine procedure for Peyronie's disease. J Urol. 2001; 166:185-188.

12. Cormio L, Zucchi A, Lorusso F, et al. Surgical treatment of Peyronie's disease by plaque incision and grafting with buccal mucosa. Eur Urol 2009; 55:1469-1475.

13. Zucchi A, Silvani M, Pastore AL, et al. Corporoplasty Using Buccal Mucosa Graft in Peyronie Disease: Is It a First Choice? Urology. 2015; 85:679-83.

14. Mulhall JP, Goldstein I, Bushmakin AG, et al. Validation of the Erection Hardness Score. J Sex Med. 2007; 4:1626-1634.

15. Bekos A, Arvaniti M, Hatzimouratidis K, et al. The natural history of Peyronie's disease: An ultrasonography-based study. 2008; 53:644-651

16. Eppley BL, Keating M, Rink R. A buccal mucosal harvesting technique for urethral reconstruction. J Urol. 1997; 157:1268.

17. Garaffa G, Kuehhas EF, De Luca F, et al. Long-term results of reconstructive surgery for Peyronie's disease. Sex Med Rev. 2015; 3:113-121.

18. Henry DG, Mahle P, Caso J, et al Surgical techniques in penoscrotal implantation of an inflatable penile prosthesis: a guide to increasing patient satisfaction and surgeon ease. Sex Med Rev. 2015; 3:36-47.

19. Viktrup L, Hayes RP, Wang P, Shen W. Construct validation of patient global impression of severity (PGI-S) and improvement (PGI-I) questionnaires in the treatment of men with lower urinary tract symptoms secondary to benign prostatic hyperplasia BMC Urology. 2012; 12:30.

20. Mulhall J, Anderson M, Parker M. A surgical algorithm for men with combined Peyronie's disease and erectile dysfunction: functional and satisfaction outcomes. J Sex Med. 2005; 2:132-8.

21. Flores S, Choi JM, Alex B, et al. Erectile dysfunction after plaque incision and grafting: short term incidence and predictors. J Sex Med. 2011; 8:2031-37.

22. Carson CC, Chun JL. Peyronie's disease: Surgical management: Autologous materials. Int J Impot Res. 2002; 14:329-35.

23. Kadioglu A, Sanli O, Akman T, et al. Graft materials in Peyronie's disease surgery: a comprehensive review J Sex Med. 2007; 4:581-95.

24. Donoff RB. Biological basis for vestibuloplasty procedures. J Oral Surg. 1976; 34:890.

25. Leone CR Jr. Conjunctivodacryocystorhinostomy with buccal mucosal graft. Arch Ophthalmol. 1995; 113:113.

26. Yarington CT Jr. Reconstruction of the base of the tongue and lateral pharyngeal wall. Laryngoscope. 1980; 90:202.

27. Lin WC, Chang CYY, Shen YY, Tsai HD. Use of autologous buc- 
cal mucosa for vaginoplasty: a study of eight cases. Hum Reprod. 2003; 18:604.

28. Shioshvili TJ, Kakonashivili AP. The surgical treatment of Peyronie's disease: replacement of plaque by free autograftof buccal mucosa. Eur Urol. 2005; 48:129-35.

29. Liu B, Zhu XW, Zhong DC, et al. Replacement of plaque by buccal mucosa in the treatment of Peyronie's disease: a report of 27 cases Zhonghua Nan Ke Xue. 2009; 15:45-7.

30. Viet QT, Dennis HK, Timothy FL, et al. Review of the surgical approachesfor Peyronie's disease: corporeal plication and plaque incision with grafting. Adv Urol. 2008; 2008:263450.

31. Porena M, Mearini L, Mearini E, et al. Peyronie's disease: corporoplasty using saphenous vein patch graft. Urol Int. 2002; 68:91-4.

32. Chang JA, Gholami SS, Lue TF. Surgical management: saphenous vein grafts. Int J Impot Res. 2002; 14:375-8.

33. Nowicki M, Buczkowski P, Miskowiak B, et al. Immunocytochemical study on endothelial integrity of saphenous vein grafts harvested by minimally invasive surgery with the use of vascular mayo stripers. A randomized controlled trial. Eur J Vasc Endovasc Surg. 2004; 27:244-50.

34. Tsui LC, Souza DS, Filbey D, et al. Localization of nitric oxide synthase in saphenous vein grafts harvested with a novel "no-touch" technique: potential role of nitric oxide contribution to improved early graft patency rates. J Vasc Surg. 2002; 35:356-62.

35. Brannigan RE, Kim ED, Oyasu R, et al. Comparison of tunica albuginea substitutes for the treatment of Peyronie's disease. J Urol. 1998; 159:1064-8.

36. Kadioglu A, Sanli O, Akman T, et al. Surgical treatment of Peyronie's disease: a single center experience with 145 patients. Eur Urol. 2008; 53:432-40.

37. Kalsi J, Minhas S, Christopher N, et al. The results of plaque incision and venous grafting (Lue procedure) to correct the penile deformity of Peyronie's disease. BJU Int. 2005; 95:1029-33.

38. Montorsi F, Salonia A, Briganti A, et al. Five year follow-up of plaque incision and vein grafting for Peyronie's disease. J Urol. 2004; 171:331.

39. El-Sakka AI, Rashwan HM, Lue TF. Venous patch graft for Peyronie's disease. Part II: outcome analysis. J Urol. 1998; 160:2050-3.

40. Akman T, Sanli O, Gurkan L, et al. Medial dissection of the neuro vascular bundle in Peyronie's patients with dorsal curvature: Demonstration of a technique and analysis of outcome. In Abstracts of 8th Congress of the European Society for Sexual Medicine 2006; p. 1, A:V-01-001.

41. Adeniyi AA, Goorney SR, Pryor JP, et al. The Lue procedure: an analysis of the outcome in Peyronie's disease. BJU Int. 2002; 89:404-8.

42. Akkus E, Ozkara H, Alici B, et al. Incision and venous patch graft in the surgical treatment of penile curvature in Peyronie's disease. Eur Urol. 2001; 40:531-6.

43. De Stefani S, Savoca G, Ciampalini S, et al. Saphenous vein harvesting by 'stripping' technique and ' $W$ '-shaped patch covering after plaque incision in treatment of Peyronie's disease. Int J Impot Res. 2000; 12:299-301.

44. Yurkanin JP, Dean R, Wessells H. Effect of incision and saphenous vein grafting for Peyronie's disease on penile length and sexual satisfaction. J Urol. 2001; 166:1769-72.

45. Gvasalia B, Kochetov A, Abramov R, et al. Buccal mucosa in the surgical treatment of Peyronie's disease. J Sex Med. 2014; 11 (Suppl 1):33.

46. Costantini E, Zucchi A. Reconstructive surgery in Peyronie's disease: What's new? World J Clin Urol. 2015; 4:1-4.

47. Rolle L, Tamagnone A, Bollito E, et al. Could plaque excision surgery with sis graft induce a new fibrotic reaction in la Peyronie's disease patients? Arch Ital Urol Androl. 2007; 79:167-9.

48. Levine LA. Editorial comment on: Surgical treatment of Peyronie's disease by plaque incision and grafting with buccal mucosa. Eur Urol. 2009; 55:1475-6.

49. Kakonashivili AP, Shioshvili TJ. Substitution of tunica albuginea penis by different autotransplant: an experimental study. Georgian Med News. 2003; 10:38-42.

\section{Correspondence}

Andrea Fabiani, MD (Corresponding Author)

andreadoc1@libero.it

Lucilla Servi, MD

lucilla.servi@sanita.marche.it

Fabrizio Fioretti, MD PhD

fa.fioretti@libero.it

Valentina Maurelli, MD

valentinamaurelli@hotmail.it

Surgery Dpt, Section of Urology, ASUR Marche Area Vasta 3

Macerata Hospital, Italy

Flavia Tombolini MD, Urology Resident

flavia.tombolini@gmail.com

Urologic Clinic, Polytechnic University of Marche Region, Italy

Alessandra Filosa, MD PhD

alessandrafilosa@yahoo.it

Section of Pathological Anatomy, Department of Clinical Pathology,

Area Vasta 3, ASUR Marche, Macerata Hospital, Macerata, Italy

Alessandro Zucchi, MD, Associate Professor

zucchi.urologia@gmail.com

Urology and Andrology Department, University of Perugia,

S. Andrea delle Fratte, Perugia, Italy

Gianni Paulis, MD

paulisg@libero.it

Regina Apostolorum Hospital, Andrologic Center, Albano Laziale (Rome), Italy

Gabriele Mammana, MD

gabriele.mammana@sanita.marche.it

Head of Surgery Dpt, Chief of Section of Urology, ASUR Marche Area Vasta 3

Macerata Hospital, Macerata, Italy 